\title{
Age at menopause and the correlates of natural menopause among urban and rural women in the southern Nigeria
}

\author{
Eugene M. Ikeanyi*, Ebenezer H. Ikobho
}

Department of Obstetrics and Gynecology, Niger Delta University Teaching Hospital Okolobiri, Bayelsa State, Nigeria

Received: 03 February 2021

Accepted: 06 March 2021

\author{
*Correspondence: \\ Dr. Eugene M. Ikeanyi, \\ E-mail: abuchikeanyi@yahoo.com
}

Copyright: ( ) the author(s), publisher and licensee Medip Academy. This is an open-access article distributed under the terms of the Creative Commons Attribution Non-Commercial License, which permits unrestricted non-commercial use, distribution, and reproduction in any medium, provided the original work is properly cited.

\begin{abstract}
Background: Menopause, the point in a woman's life when permanent cessation of cyclical menstruation occurs for a period of 12 months due to the loss of ovarian activity marking the end of reproductive lifespan and potential. Natural menopause is a physiological event, universal women phenomenon and irreversible part of the entire normal aging process. It brings the menopausal woman for preventive health care services due to its associated health implications. This study sought to investigate the age at menopause and its correlates in southern Nigerian women.

Methods: A cross-sectional survey of datasets of women from two different communities attending annual religious conference was conducted using tested semi-structured researcher-administered questionnaire in 2019.

Results: Data was analyzed on 152 participants from an urban and a rural communities. Mean chronological age was $58.8 \pm 8.8$ years and parity was 6.4 \pm 2.2 . Mean age at menopause was 50.0 \pm 4.6 years, median (IQR) 50.0 (47-53) and 49.2 \pm 4.7 versus $50.5 \pm 4.5$ and median (IQR) 49.5 (46-51) and 50.5 (47-54) for urban and rural participants respectively. $1.3 \%, 9.2 \%, 69.7 \%$ and $19.7 \%$ were premature, early, normal and late onset menopause respectively. Risk of early onset menopause was insignificantly increased by higher education, social class, lower BMI and low parity. Forgetfulness (20.3\%), irritability (19.5\%), hot flushes $(17.3 \%)$ and insomnia (16.5\%) were the leading symptoms. Main complications were chronic hypertension $62(40.8 \%)$, diabetes mellitus $12(7.9 \%)$ and $4(2.6 \%)$ recent fractures.

Conclusions: Age at menopause was moderate, early menopause was rather high, programmed preventive healthcare services should address modifiable risk factors. Cancer screening services for late onset women is equally crucial.
\end{abstract}

Keywords: Age at natural menopause, Community, Correlates, Early, Factors, Survey

\section{INTRODUCTION}

Reproductive potential in the female is signalled at menarche and terminates at menopause. At about the $20^{\text {th }}$ week of female intrauterine life a fixed ovarian capita of about five to seven million oocytes is achieved and reduced to about two million at birth. ${ }^{1}$ The reserve is subsequently gradually, at first; in the pre-pubertal stage of life, continues to be irregularly recruited, destroyed and reduced. Later this becomes cyclical from puberty till it is substantially reduced in menopausal transition marked by irregular ovulation and menstrual cycles before the final exhaustion of the reserve and termination of menstruation at menopause normally in forties to fifties. The ovary is basically the seat of the oocytes enveloped by granulosa and theca cells forming the ovarian follicles that produce the female sex hormones; estrogen and progesterone, in addition testosterone and inhibin. The estrogen and progesterone control menstruation while estrogen plays role in calcium metabolism and maintenance of body cholesterol. At the exhaustion of oocytes and in deed the follicles, the cyclical sex hormones secretion controlling the menstrual cycle and ovulation cease terminating the female reproductive phase of life. It occurs naturally from chronological age of 40 years bringing with it a dynamic neuroendocrine changes. From the perimenopausal (menopause transition) stage there is a progressive 
reduction of ovarian activities for 8-10 years with attendant irregular ovulation and menstrual cycle till menopause; the point one year of final exhaustion of ovarian reserve and cessation of menses with consequent physical and psychological manifestations. In the postmenopausal period after the one year amenorrhea, symptoms abate in some women but may continue for 10 years or longer in others. At this late stage there is an increased risk of osteoporosis and cardiovascular diseases. Menopause with the exhaustion of the ovarian follicles and markedly reduced sex hormones especially the potent estradiol, there is a consequent manifestations of its lack; vasomotor symptoms, atrophy of the estradiol sensitive breast, urogenital organs, bone matrix loss and disorders of the cardiovascular system. The mean age at menopause has remained at 51 years from the ancient times. $^{2}$ Menopause is considered premature if it occurs before 40 years, early onset if it occurs before 45 years and late onset if it occurs at 55 years and older. ${ }^{3,4}$ Each of these classes has its attendant problems. Natural menopause is diagnosed after 12 consecutive months of absence of menstrual flow in a woman forty years or older in the absence of implicating medical treatment or genital tract surgical treatment(bilateral oophorectomy or and hysterectomy), endocrinopathy or genital tract pathology. ${ }^{1,4}$ Nicky Panay defined menopause as the last menstrual period after a minimum of one year's amenorrhea. ${ }^{2}$ Few factors are known to lower the age of natural menopause and include smoking, living at high altitude, autoimmune disorders, premutation Fragile $\mathrm{X}$ carrier. $^{5-6}$

Globally the population is tending towards a rectangular society with a good proportion of women surviving to postmenopausal age with its attendant health challenges.

This survey was carried out to investigate the correlates of menopause among southern Nigerian women.

\section{METHODS}

A multicenter population based cross-sectional study of menopausal women among the conferencing women was conducted in two selected communities in Benin City Edo state in South-south and Umunnachi town in Anambra state in South-east both in southern region of Nigeria between June and August 2019. Benin City is the capital of Edo state and an urban setting with heterogeneous population from within Edo state, neighboring states and other parts of Nigeria. Umunnachi is a rural setting in Anambra central senatorial zone with a homogenous indigenous Igbo population. Data was collected using pretested semi-structured intervieweradministered questionnaire. Two medical personnel and two nurses assisted in each site in collecting the data. The questionnaire had sections on sociodemographic characteristics (age, parity, education, spouse occupation and marital status), menopausal symptomatology, weight in kilogram, height in centimeter, blood pressure in $\mathrm{mmHg}$. The last menstrual period is the date of the onset of the last or final normal menstrual flow (LNMP) while menopause by world health organization is diagnosed one year after the final cessation of menses or LNMP. ${ }^{1,6}$ Menopause will be classified as premature if it occurred $<40$ years of age, early onset if it occurred 40-44 years of age, normal if it occurred $45-54$ years and late onset $\geq 55$ years.

Each participant was counselled, ensured confidentiality and verbally consented to the interview and clinical evaluation (weight, height and blood pressure measurement). The centers permitted the survey.

The women who had surgical menopause; hysterectomy and or bilateral oophorectomy, on hormone replacement therapy, long term hormonal contraception, combined oral contraception (COCP) were excluded from the study.

The sample size was scientifically determined according to the formula by Cochrane using a known early onset menopause prevalence of $9.4 \%{ }^{3}$ as below: ${ }^{7}$

$\mathrm{n}=\frac{\mathrm{z}^{2} \mathrm{pq}}{\mathrm{d}^{2}}$

Where $\mathrm{P}=$ Maximum known early onset menopause prevalence in literature,

$q=1-p($ complement of $p)$.

$\mathrm{d}=$ Allowable error margin of estimate (precision) $=$ 0.05 ,

$\mathrm{Z}=$ this is $\mathrm{Z}$ statistics for $95 \%$ confidence level (value for selected alpha level $\alpha=0.05$ which is conventionally 1.96 . $\mathrm{n}=$ sample of the participants i.e. sample size $=131$

To further increase the power of the study the sample size was increased to 152 to allow for attritions. The sample was drawn using simple random sampling approach.

Data was fed in and analysed with EPI Info version 3.5.1 and the descriptive statistics presented in table and figure in frequency and percentages. Association of variables was determined with Fishers exact test and statistical significance was $\mathrm{p}<0.05$.

\section{RESULTS}

Table 1 shows the characteristics of the participants. With the exception of statistically significant older $(\mathrm{p}<0.001)$ and higher rate of widowhood $(\mathrm{p}=0.0047)$ among the urban subset the two subsets were similar in sociodemographic. 
Table 1: Characteristics of participants $(n=152)$.

\begin{tabular}{|c|c|c|c|c|c|c|}
\hline \multirow[b]{2}{*}{ Characteristic } & \multirow[b]{2}{*}{ Variable } & \multicolumn{2}{|c|}{ Frequency (\%) } & \multirow[b]{2}{*}{$\begin{array}{l}\text { Total } \\
152\end{array}$} & \multirow[b]{2}{*}{$\begin{array}{l}\mathbf{R R}, 95 \% \\
\text { confidence interval }\end{array}$} & \multirow[b]{2}{*}{ P value } \\
\hline & & $\begin{array}{l}\text { Urban } \\
(\mathbf{n}=60)\end{array}$ & $\begin{array}{l}\text { Rural } \\
(\mathrm{n}=92)\end{array}$ & & & \\
\hline \multirow{6}{*}{$\begin{array}{l}\text { Chronological age } \\
\text { (years) }\end{array}$} & $40-44$ & 0 & 4 & 4 & & \multirow{6}{*}{$<0.001$} \\
\hline & $45-49$ & 4 & 16 & 20 & & \\
\hline & $50-54$ & 4 & 26 & 30 & & \\
\hline & $55-59$ & 16 & 16 & 32 & & \\
\hline & $60-64$ & 16 & 12 & 28 & & \\
\hline & $\geq 65$ & 20 & 18 & 38 & & \\
\hline Age (years) & Median (IQR) & $62.0(57-69)$ & $54.5(50-62)$ & & & 0.0003 \\
\hline \multirow{2}{*}{ Parity } & $\leq 4$ & $12(20.0)$ & $20(21.7)$ & 32 & 0.94 & \multirow{2}{*}{0.84} \\
\hline & $\geq 5$ & $48(80.0)$ & $72(78.3)$ & 120 & & \\
\hline Parity (years) & Median (IQR) & $7(5-9)$ & $6(5-8)$ & - & & 0.055 \\
\hline \multirow{2}{*}{ Marital status } & Married & $32(53.3)$ & $70(76.1)$ & 102 & $0.56,0.38-0.82$ & \multirow{2}{*}{0.005} \\
\hline & Widowed & $28(46.7)$ & $22(23.9)$ & 50 & & \\
\hline \multirow{2}{*}{ Educational status } & $\leq$ Secondary & $48(80.0)$ & $64(69.6)$ & 112 & 1.4 & \multirow{2}{*}{0.19} \\
\hline & $>$ Secondary & $12(20.0)$ & $28(30.4)$ & 40 & & \\
\hline \multirow{3}{*}{ Social class } & Upper & $12(20.0)$ & $22(23.9)$ & 34 & & \multirow{3}{*}{0.181} \\
\hline & Middle & $6(10.0)$ & $18(19.6)$ & 24 & & \\
\hline & Lower & $42(70)$ & $52(56.5)$ & 94 & & \\
\hline \multirow{4}{*}{$\begin{array}{l}\text { Body mass index } \\
\left(\mathrm{kg} / \mathrm{m}^{2}\right)\end{array}$} & $<18.5$ & $2(3.3)$ & $2(2.2)$ & 4 & & \multirow{4}{*}{0.89} \\
\hline & $18-5-24.9$ & $14(23.3)$ & $18(19.6)$ & 32 & & \\
\hline & $25-29.9$ & $16(26.7$ & $28(30.4)$ & 44 & & \\
\hline & $\geq 30$ & $28(46.7)$ & $44(47.8)$ & 72 & & \\
\hline \multirow{5}{*}{$\begin{array}{l}\text { Age at LNMP } \\
\text { (years) }\end{array}$} & $<45$ & $10(16.7)$ & $10(10.9)$ & 20 & & \multirow{5}{*}{0.45} \\
\hline & $45-49$ & $22(36.6)$ & $40(43.47)$ & 62 & & \\
\hline & $50-54$ & $20(33.3)$ & $24(26.08)$ & 44 & & \\
\hline & $55-59$ & 8 & $16(17.4)$ & 24 & & \\
\hline & $\geq 60$ & 0 & $2(2.2)$ & $2(1.3)$ & & \\
\hline \multirow{4}{*}{$\begin{array}{l}\text { Age at menopause } \\
\text { (years) }\end{array}$} & $<40$ & 2 & 0 & $2(1.3)$ & & \multirow{4}{*}{0.07} \\
\hline & $40<45$ & 8 & 6 & $14(9.2)$ & & \\
\hline & $45-54$ & 42 & 64 & $106(69.7)$ & & \\
\hline & $\geq 55$ & 8 & 22 & $30(19.7)$ & & \\
\hline
\end{tabular}

Table 2: Characteristics influencing age at early menopause $(n=152)$.

\begin{tabular}{|c|c|c|c|c|c|}
\hline Characteristic & Variable & $\begin{array}{l}\text { Early 40-44 years, } \\
\mathbf{N}(\%)(n=14)\end{array}$ & $\begin{array}{l}\geq 45 \text { years } \\
N(\%)(n=138)\end{array}$ & $\mathrm{RR}, 95 \% \mathrm{CI}$ & $P$ value \\
\hline \multirow{2}{*}{ Education } & $\leq$ Secondary & $10(71.4)$ & $102(73.9)$ & $0.89,0.30-2.7$ & \multirow{2}{*}{0.76} \\
\hline & $>$ Secondary & $4(28.6)$ & $36(26.1)$ & & \\
\hline \multirow{3}{*}{ Social class } & Upper & $4(28.6)$ & $30(21.7)$ & $1.4,0.28-7.1$ & 1.0 \\
\hline & Middle & $2(14.3)$ & $22(15.9)$ & & Ref \\
\hline & Lower & $8(57.1)$ & $86(63.2)$ & $1.02,0.23-4.5$ & 1.0 \\
\hline \multirow{2}{*}{ BMI } & $<30$ & $10(71.4)$ & $70(50.7)$ & $2.3,0.74-6.9$ & \multirow{2}{*}{0.17} \\
\hline & $\geq 30$ & $4(28.6)$ & $68(49.3)$ & & \\
\hline \multirow{2}{*}{ Parity } & $\leq 4$ & $4(28.6)$ & $28(20.3)$ & $1.5,0.5-4.5$ & \multirow{2}{*}{0.49} \\
\hline & $\geq 5$ & $10(62.5)$ & $110(79.7)$ & & \\
\hline
\end{tabular}

Median (IQR) chronological age of the participants at the time of the study was 58.5 (interquartile range 51.5-64.5) years while the mean age was $58.8 \pm 8.8$ with the range 43-81 years. The urban subset were significantly older; median and IQR 62 (57-69) versus 54.5 (50-62) years while their mean age $(62.0 \pm 8.0$, ranged $47-77$ versus $56.8 \pm 8.7$, ranged $43-81, \mathrm{p}<0.001)$. The median parity of the participants was 6 and the (interquartile range 5-8 while the subsets urban versus rural 7.0 (5-9) versus 6.0 $(5-8)$. The subsets were statistically similar in parity 
$(\mathrm{p}=0.06)$. The median age at last normal menstrual period (LNMP) of the participants was 48.5 IQR (46-52). The values for the urban and the rural subsets was 48.5 IQR (45-50) years and 48.5 IQR (46-54) years respectively. The age at LNMP was comparable in the subsets $(p=0.45)$. The mean age at menopause (one year after the LNMP) of the participants was $50.0 \pm 4.6$ years, median and interquartile range (IQR) 50.0 (47-53) years. The values for the urban subset were 49.2 $\pm 4.7,49.5$ IQR (4651) years while $50.5 \pm 4.5$ and $50.5(47-54)$ years for the rural subset. The observed difference in mean age at the menopause was statistically comparable $(\mathrm{p}=0.07)$. About one of every ten $(9.2 \%)$, seven in ten $(69.7 \%)$ and one in five $(19.7 \%)$ of the participants had early, normal and late menopause respectively. Two participants $(1.3 \%)$ had premature menopause. The subsets were similar in the distribution of the timing of menopause $(\mathrm{p}=0.07)$.

Table 2 shows the influence of selected characteristics on onset of natural menopause. Lower educational status was associated with about $11 \%$ reduction in the risk of early onset menopause but not to a statistical significant level $(p=0.76)$. Social class is directly associated with early onset menopause. This however, was not statistically significant $(\mathrm{p}=1.0)$. Low body mass index (BMI) was more than twice associated with early onset menopause. However, the observed association was not statistical significant $(\mathrm{p}=0.17)$. Similarly, low parity increased the risk of early onset menopause by $50 \%$, nonetheless, this was not statistically significant $(\mathrm{p}=0.49)$.

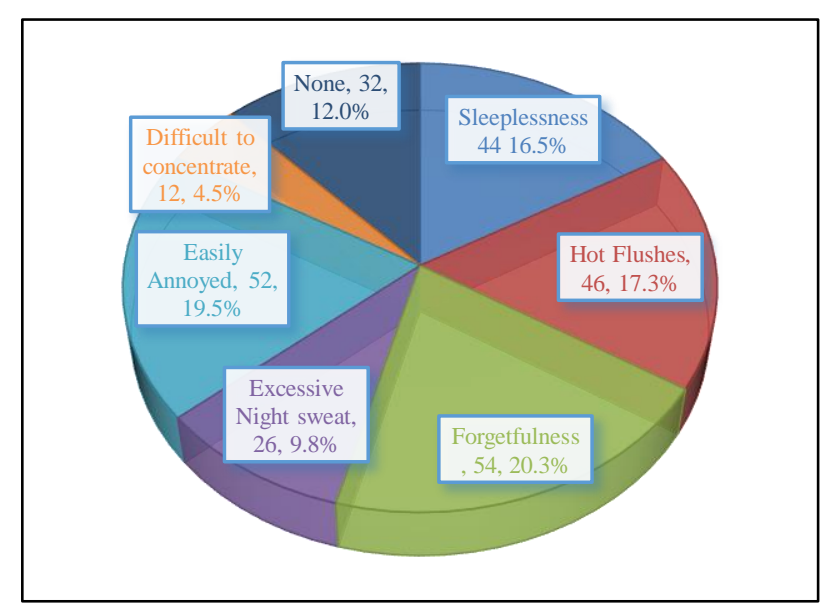
Figure 1: Participants reported menopausal
symptoms.

Figure 1 shows the menopausal symptoms reported by the participants. The commonest symptom was forgetfulness (20.3\%) followed by easily annoyed/ irritability $(19.5 \%)$, hot flushes $(17.3 \%)$ and insomnia $(16.5 \%)$.

Sixty two $(40.8 \%)$ of the participants had chronic hypertension, type 2 diabetes mellitus $12(7.9 \%)$ and recent fracture $4(2.6 \%)$.

\section{DISCUSSION}

The mean chronological age of the participants at the time of this survey was $58.8 \pm 8$.8 years with the range 43 81 years. Except having more widows and being older at the time of the survey the urban subset was generally similar to the rural in the other assessed sociodemographic characteristics $(\mathrm{p}>0.05)$.

The median age of the participants at their last natural menstrual period was $48.51 \mathrm{QR}$ (46-52) years while the values were 48.5 IQR (45-50) years and 48.5 IQR (4654 ), mean $48.3 \pm 4.5$ and $49.3 \pm 4.7$ for the urban and the rural subsets respectively.

The mean age at menopause (one year after the LNMP) of the participants was 50.0 44.6 years and median and interquartile range (IQR) 50.0 (47-53) years. The mean age of 50.0 years at menopause of the participants was in agreement with other reports. ${ }^{4,8,9}$ and 2.8 years earlier than that reported over three decades earlier in southwest Nigeria but higher than one other report from another community in the same region about the same period and one report from the southeastern region. ${ }^{10-12}$ The value was over one year earlier than reports from industrialized countries. ${ }^{1,13}$ The figure was higher than a report from the northern Nigeria. ${ }^{14}$ The timing of menopause vary among industrialized-non-industrialized populations. ${ }^{1,13}$ Ethnicity, living altitude, nutritional status and genetics, socioeconomic status particularly early life Socioeconomic status, racial/ethnic, lifestyle background like cigarette smoking and alcoholic intake influence the timing of menopause. ${ }^{1,15}$

The values for the urban subset were $49.2 \pm 4.7$ years, 49.5 interquartile range (46-51) years and 50.5 $\pm 4.5,50.5$ (4754) years for the rural subset. Though the two groups were statistically similar $(\mathrm{p}=0.07)$ in age at menopause the rural subset were slightly older at menopause contrary to other reports. ${ }^{1,16}$ This could be attributable to the heterogeneity of the two studied populations. The rural subset though were recruited in a rural setting, was made of rural dwellers and urban returnees for the purpose of their annual conference meeting and therefore were not a true rural population. However, the rural subset was all Igbo ethnic group in Anambra state unlike the urban subset made of women from many different ethnic groups in Nigeria. Ethnicity has been associated with the timing of age at menopause. ${ }^{1,3}$

From this study the prevalence of premature menopause was $1.3 \%$, lower than $1.7-2.8 \%$ in other reports. ${ }^{3,4}$ Primary ovarian insufficiency; a cause of premature menopause, is a condition defined by the depletion or dysfunction of ovarian follicles with the cessation of menses before age 40 years. ${ }^{5}$ This study did not explore the causes of the premature menopause. Early menopause occurred in $9.2 \%$ and this was within a range of $4.9-9.4 \%$ from a Western multinational data. ${ }^{4}$ This was contrary to the current evidence supporting increasing age at 
menopause. $^{3,17}$ Our reported prevalence of early onset menopause was lower than a report of a prevalence of $22.9 \%$ from northern Nigeria. ${ }^{18}$ The latter was on a hospital based data on human immunodeficiency virus (HIV) positive women with an accruing evidence of association of HIV with early menopause. ${ }^{18,19}$

There was an insignificant increase of the risk of early onset menopause by higher social class. This was in contrast to another report. ${ }^{1}$ Higher education, corroborating another report from Nigeria, was associated with increased risk of early menopause, contrary to other reports. ${ }^{1,14,16,20}$ Similarly, low BMI was associated with early age at menopause in consonant with another report. $^{14}$ The contrary was true of increased BMI association with later age at natural menopause and consistent with other report. ${ }^{1,21,22}$ Low parity was associated with the increased risk of early menopause and the contrary was true for high parity consistent with other reports. ${ }^{1,14,22}$ It is in the literature that nulliparity significantly associated with premature and early menopause. ${ }^{4}$ If early menopause is associated with higher education, social class and lower parity all the tendencies of modern world ,it then implies that there is a global shift towards earlier rather than delayed onset of menopause contrary to other reports in the literature. ${ }^{3,17}$ This finding corroborates the theory that natural menopause results following the sufficient depletion of oocytes. ${ }^{1,23}$ Unlike the high parity state, the more frequent ovulation in low parity exhausts the ovarian reserves earlier. In addition, the more educated and therefore higher social class in our setting are more likely to have lower parity. ${ }^{24}$

However, higher body mass index and the wider use of hormonal contraception may attenuate this effect and increase the age at menopause observed in industrialized populations. Conditions that negatively influence or suppress ovulation like prolonged use of hormonal contraception, frequent pregnancies or high parity, lactation and obesity will to varying degrees be expected to delay menopause. Undernourished women experience earlier menopause as it is evident that body fat plays role or contributes to estrogen production. Unlike later age at menopause, early menopause has increased risk of adverse health implications like chronic disorders later in the lifetime like type 2 diabetes mellitus, cardiovascular disease including ischemic heart diseases, osteoporosis and therefore increased risk of early death. ${ }^{1,25}$

The leading menopausal symptoms experienced by the participants were forgetfulness $(20.3 \%)$, irritability (19.5\%), hot flashes (17.3\%) and insomnia (16.5\%). About one out of every eight $(12.0 \%)$ of the participants had symptom free menopause. These symptoms were similarly reported by other workers. ${ }^{12}$

Menopausal period is a hypo-estrogenic state. Estrogen protects premenopausal women from cardiovascular diseases through favourable high density-low density lipoprotein ratio, through nitric oxide mediated vasodilatation that increases myocardial blood flow, by its antioxidant effect on endothelial cells and by directly decreasing the risk of aortic atheroma. ${ }^{2}$ As many as $40.8 \%$ of the participants were hypertensive because of the loss of these protective benefits of ovarian estrogen.

Early menopause; early loss of ovarian function has a number of health implications for the woman ranging from, bone skeletal loss through cardiovascular disorders to diabetes mellitus while late onset subset runs the risk of breast, ovarian and endometrial cancers. ${ }^{1,22}$ Early onset menopause is associated with increased risk of ischemic heart disease, osteoporosis, cardiovascular disorder, earlier decline in cognitive function. ${ }^{1,25}$ In the absence of estrogen there is reversal of estrogenic osteoblastic to osteoclastic bone action with consequent increase loss of bone mineral and accidental fractures as recorded in this data. Similarly early loss of endogenous estrogen results in alteration of serum lipid in favour of low density lipoprotein and rise in the risk of ischemic heart disease and hypertensive disorder. About two fifths of the participants were hypertensive in this study.

The prevalence of late menopause in this data was $19.7 \%$. Much as the later age at menopause is protective against the health disorders attributable to the early onset menopause as documented above and therefore longer overall survival and life expectancy, nonetheless it is associated with increased risk of endometrial, breast and ovarian cancers. ${ }^{1}$ It is evident from the literature that later age older than 46.5 years at menopause significantly associated with increased risk of endometrial cancer. ${ }^{22}$ The unopposed estrogenic action of frequent anovulatory cycles in late menopause increases the risk of endometrial, breast and ovarian cancers in women with late loss of ovarian function. Non progesterone opposed estrogenic action results in endometrial cells mitotic activities with increased risk of deoxyribonucleic acid (DNA) damage. ${ }^{22}$ Again the later age at menopause exposes the endometrial stem cells to both spontaneous and environmental mutation. In addition, the late menopausal women have higher hormone levels and longer exposure to estrogen before menopause. ${ }^{22}$

Menopause varies among the women in age of occurrence, manifestation and adaptability. Timing of the onset of menopause; the onset and duration of perimenopausal or menopause transition period and timing of the final natural menstrual period and postmenopausal period following the one year of permanent cessation of menstruation and the rest of the woman's life after menopause are the areas of research interests.

This data relied substantially on retrospective memory recall fraught with distortion of the facts. This is the reason a prospective longitudinal study design would ensure more authentic evidence as it provides the privilege to follow-up the women to have a real-time 
observation and record of their experiences as they occur. The strength of this study lied in its community population and not hospital based data. In addition the sample size was scientifically determined.

\section{CONCLUSION}

The median age at menopause was 50.0 years, early menopause was common and it was supported by conditions that enhance frequent ovulation. Sensitization and organized preventive healthcare services are proffered from perimenopausal period for quality care.

Funding: No funding sources

Conflict of interest: None declared

Ethical approval: The study was approved by the Institutional Ethics Committee

\section{REFERENCES}

1. Gold EB. The timing of the age at which natural menopouse occurs. Obstet Gynecol Clin North Am. 2011;38(3):425-40.

2. Panay N. Menopause and postmenopausal health. In: Edmonds DK, Lees C, Bourne T, eds. Dewhurst's textbook of obstetrics and gynaecology. 9th edn. Wiley Blackwell: 2018:672-688.

3. Choe SA, Sung J. Trends of premature and early menopause: a comparative study of the US national health and nutrition examination survey and the Korea national health and nutrition examination survey. J Korean Med Sci. 2020;35(14):e97.

4. Mishra GD, Pandeya N, Dobson AJ, Chung HF, Anderson D, Kuh D, et al. Early menarche, nulliparity and the risk for premature and early natural menopause. Hum Reprod. 2017;32(3):679-86.

5. Committee Opinion. Primary Ovarian Insufficiency in Adolescents and Young Women. The American College of Obstetricians and Gynecologists Women's Health Care Physicians. Number 605. 2014.

6. World Health Organization. Research on the menopause in the 1990s. World Health Organization: Geneva (Switzerland); 1996.

7. Cochran WG. Sampling techniques 3rd edn. New York: John Wiley and Sons; 1977.

8. OlaOlorun F, Lawoyin T. Age at menopause and factors associated with attainment of menopause in an urban community in Ibadan, Nigeria. J Climacteric. 2009;12(4):352-63.

9. Ozumba BC, Obi SN, Obikili E, Waboso P. Age, symptoms and perception of menopause among Nigerian women. Obstet Gynecol India. 2004;54(6):575-8.

10. Otolorin EO, Adeyefa I, Osotimehin BO, Fatinikun T, Ojengbede O, Otubu JO, et al. Clinical, hormonal and biochemical features of menopausal women in Ibadan, Nigeria. Afr J Med Sci. 1989;18(4):251-5.
11. Okonofua FE, Lawal A, Bamgbose JK. Features of menopause and menopausal age in Nigerian women. Int J Gynecol Obstet. 1990;31(4):341-5.

12. Ugwu UM, Umeora OUJ, Ejikeme BN Patterns of menopausal symptoms and adaptive ability in a rural population in South-east Nigeria J Obstet Gynecol. 2009;28(2):217-21.

13. Gold EB, Bromberger J, Crawford S, Samuels S, Greendale GA, Harlow SD, et al. Factors associated with age at natural menopause in a multiethnic sample of midlife women. Am J Epidemiol. 2001;153(9):865-74.

14. Achie LN, Olorunshola KV, Mabrouk M. Age at natural menopause among Nigerian Women in Zaria, Nigeria. Asian J Med Sci. 2011;3(8):151-3.

15. Hardy R, Kuh D. Social and environmental conditions across the life course and age at menopause in a British birth cohort study. BJOG. 2005;112:346-54.

16. Castelo-Branco C, Blümel JE, Chedraui P, Calle A, Bocanera R, Depiano E, et al. Age at menopause in Latin America. Menopause. 2006;13(4):706-12. Erratum in: Menopause 2006;13:850.

17. Nichols HB, Trentham-Dietz A, Hampton JM, TitusErnstoff L, Egan KM, Willett WC, et al. From menarche to menopause: trends among US Women born from 1912 to 1969 . Am J Epidemiol. 2006;164(10):1003-11.

18. Agaba P, Meloni S, Sule H, Ocheke A, Agaba E, Idoko $\mathrm{J}$, et al. Factors associated with early menopause among women in Nigeria. J Virus Erad. 2017;3(3):145-51.

19. Calvet GA, Grinsztejn BG, Quintana Mde S, Alves MR, Veloso dos Santos VG, Friedman RK, et al. Predictors of early menopause in HIV-infected women: a prospective cohort study. Am J Obstet Gynecol. 2015;212:765.e1-13.

20. Lawlor DA, Ebrahim S, Smith GD. The association of socio-economic position across the life course and age at menopause: the British women's heart and health. Br J Obstet Gynecol. 2003;110(12):1078-87.

21. Zhu D, Chung HF, Pandeya N, Dobson AJ, Kuh D, Crawford SL, et al. Body mass index and age at natural menopause: an international pooled analysis of 11prospective studies. Eur J Epidemiol. 2018;33(8):699-710.

22. Wu Y, Sun W, Liu H, Zhang D. Age at menopause and risk of developing endometrial cancer: a meta-analysis. BioMed Res Int. 2019;2019:1-3.

23. Soberon J, Calderon JJ, Goldzieher JW. Relation of parity to age at menopause. Am J Obstet Gynecol. 1966;96:96-100.

24. Maduabuchukwu IE, Ayuba II. Grandmultiparity: the reasons women give for high parity in south-south Nigeria. Clin Med Res. 2017;6(3):92.

25. Muka T, Oliver-Williams C, Kunutsor S, Laven JS, Fauser BC, Chowdhury R, et al Association of age at onset of menopause and time since onset of menopause with cardiovascular outcomes, intermediate vascular traits, and all-cause mortality: a systematic review and meta-analysis. JAMA Cardiol. 2016;1:767-76.

Cite this article as: Ikeanyi EM, Ikobho EH. Age at menopause and the correlates of natural menopause among urban and rural women in the southern Nigeria. Int J Reprod Contracept Obstet Gynecol 2021;10:1266-71. 